\title{
Concomitant ablation of atrial fibrillation in rheumatic mitral valve surgery
}

\author{
Wan Kee Kim, MD, Ho Jin Kim, MD, Joon Bum Kim, MD, PhD, Sung-Ho Jung, MD, PhD, \\ Suk Jung Choo, MD, PhD, Cheol Hyun Chung, MD, PhD, and Jae Won Lee, MD, PhD
}

\section{ABSTRACT}

Objective: Efficacy of atrial fibrillation ablation in rheumatic mitral valve disease has been regarded inferior to that in nonrheumatic diseases. This study aimed to evaluate net clinical benefits by the addition of concomitant atrial fibrillation ablation in rheumatic mitral valve surgery.

Methods: Among 1229 consecutive patients with atrial fibrillation from 1997 to $2016(54.4 \pm 11.7$ years; $68.2 \%$ were female $), 812(66.1 \%)$ received concomitant ablation of atrial fibrillation (ablation group), and 417 (33.9\%) underwent valve surgery alone (no ablation group). Death and thromboembolic events were compared between these groups. Mortality was regarded as a competing risk to evaluate thromboembolic outcomes. To reduce selection bias, inverse probability of treatment weighting methods were performed.

Results: Freedom from atrial fibrillation occurrence at 5 years was $76.5 \% \pm 1.8 \%$ and $5.3 \% \pm 1.1 \%$ in the ablation and no ablation groups, respectively $(P<.001)$. The ablation group had significantly lower risks for death (hazard ratio $[\mathrm{HR}], 0.69 ; 95 \%$ confidence interval $[\mathrm{CI}], 0.52-0.93)$ and thromboembolic events (HR, 0.49; 95\% CI, 0.32-0.76) than the no ablation group. Time-varying Cox analysis revealed that the occurrence of stroke after surgery was significantly associated with death (HR, 3.97; 95\% CI, 2.36-6.69). In subgroup analyses, the reduction in the composite risk of death and thromboembolic events was observed in all mechanical ( $\mathrm{n}=829$; HR, 0.53; 95\% CI, 0.390.73 ), bioprosthetic replacement $(\mathrm{n}=239$; HR, 0.67; 95\% CI, 0.41-1.08), and repair $(\mathrm{n}=161 ; \mathrm{HR}, 0.17 ; 95 \%$ CI, 0.06-0.52) subgroups $(P$ for interaction $=.47)$.

Conclusions: Surgical atrial fibrillation ablation during rheumatic mitral valve surgery was associated with a lower risk of long-term mortality and thromboembolic events. Therefore, atrial fibrillation ablation for rheumatic mitral valve disease may be a reasonable option. (J Thorac Cardiovasc Surg 2019;157:1519-28)

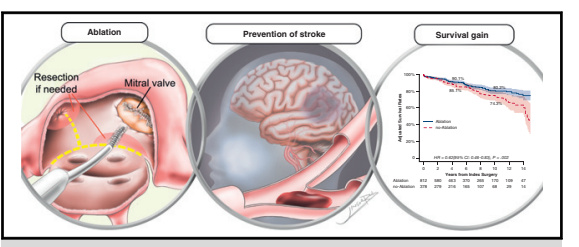

Survival benefit by the addition of surgical AF ablation for rheumatic heart disease. Central Image was illustrated by Jinsoo Rhu.

Central Message

The addition of surgical $\mathrm{AF}$ ablation for patients undergoing rheumatic MV surgery may be a reasonable option.

\section{Perspective}

Although the efficacy of AF ablation in rheumatic MV disease has been reported to be inferior to that in nonrheumatic diseases in terms of the elimination of $\mathrm{AF}$, whether there are net clinical benefits of concomitant AF ablation in rheumatic MV surgery has been debated.

See Commentaries on pages 1529 and pages 1531 .
Atrial fibrillation (AF) is frequently accompanied with mitral valve (MV) disease and has been proven to significantly contribute to death and stroke. ${ }^{1,2}$ To reduce risks

\footnotetext{
From the Department of Thoracic and Cardiovascular Surgery, Asan Medical Center, University of Ulsan College of Medicine, Seoul, South Korea.

This study was supported by a grant from the Asan Institute for Life Sciences, Asan Medical Center, Seoul, Korea.

Institutional Review Board approval at Asan Medical Center: 2016-0862.

Received for publication April 17, 2018; revisions received Aug 29, 2018; accepted for publication Sept 8, 2018

Address for reprints: Jae Won Lee, MD, PhD, Department of Thoracic and Cardiovascular Surgery, Asan Medical Center, University of Ulsan College of Medicine, 88 Olympic-ro 43-gil, Songpa-gu, Seoul 05505, South Korea (E-mail: jwlee@amc. seoul.kr).

$0022-5223 / \$ 36.00$

Copyright (c) 2018 by The American Association for Thoracic Surgery

https://doi.org/10.1016/j.jtcvs.2018.09.023
}

for these disastrous events, the importance of sinus rhythm restoration during MV surgery has been well established. $^{3-5}$ Surgical ablation of AF has been an acceptable method of converting and maintaining sinus rhythm. In addition, several studies have demonstrated that $\mathrm{AF}$ ablation is associated with an improvement in hemodynamic profiles, a reduction in thromboembolic events, and better survival. ${ }^{6-8}$

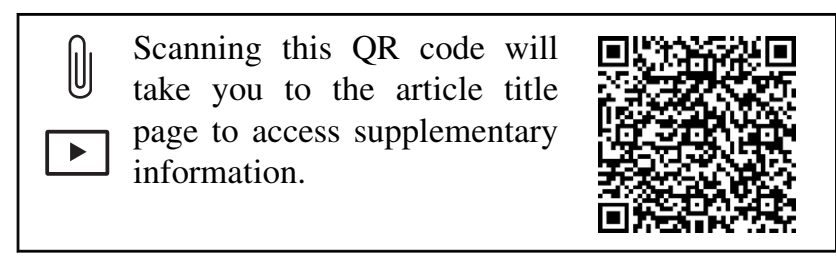




$$
\begin{aligned}
& \text { Abbreviations and Acronyms } \\
& \begin{array}{ll}
\text { AF } & =\text { atrial fibrillation } \\
\text { CI } & =\text { confidence interval } \\
\text { HR } & \text { hazard ratio } \\
\text { IPTW } & =\text { inverse probability of treatment weighting } \\
\text { IQR } & =\text { interquartile range } \\
\text { LA } & =\text { left atrial } \\
\text { MV } & =\text { mitral valve } \\
\text { PS } & =\text { propensity score } \\
\text { PY } & =\text { patient-year } \\
\text { SMD } & =\text { standardized mean difference }
\end{array}
\end{aligned}
$$

Despite the proven advantages, the impact of AF ablation for rheumatic MV disease on clinical outcomes has long been debated. For instance, several studies have shown that rhythm outcomes of AF ablation in rheumatic valve disease may be worse than those of degenerative disease., ${ }^{9,10}$ This notion has been explained by rheumatic inflammatory reaction in the atria and subsequent progression to atrial fibrosis. ${ }^{11}$ These pathologic processes are likely to change the overall atrial substrates to respond more poorly to surgical ablation, which mainly targets focal triggers and macro-reentry circuits of AF.

The evaluation of the direct impact by the addition of $\mathrm{AF}$ ablation, however, is important to assess the treatment benefits of the procedure in rheumatic MV surgery. Nevertheless, a comparison between the addition of AF ablation and MV surgery alone for patients with rheumatic heart disease has been scarce. Therefore, we evaluated and present the findings of our surgical experience in patients with $\mathrm{AF}$ and rheumatic MV disease during 20 years of follow-up in an endemic area.

\section{MATERIALS AND METHODS}

\section{Study Patients and Outcome Measures}

From our institutional cardiac surgery database, we identified 1903 adult patients (aged $>17$ years) who underwent MV surgery for rheumatic disease from January 1997 to December 2016. Patients with cardiac tumor, infective endocarditis, and a history of cardiac surgery were excluded. Finally, a total of 1229 patients formed the study population, a part of which constituted the cohort of a previous study. ${ }^{12}$ The overall cohort was divided into 2 groups based on the performance of concomitant AF ablation: ablation group $(n=812)$ and no ablation group $(n=417)$.

The primary outcomes of interest were survival and freedom from thromboembolic events. Early mortality was defined as that occurring inhospital or within 30 days of surgery. The secondary outcome of interest was the composite of valve-related complications, including reoperation of the MV, thromboembolic events, anticoagulation-related bleeding complications, and infective endocarditis as defined in the Society of Thoracic Surgeon Guidelines. ${ }^{13}$ For further measure, freedom from late ( $\geq 90$ days postoperatively) $\mathrm{AF}$ rates in the ablation and the no ablation groups were compared.

The study protocol was approved by the Institutional Review Board of the Asan Medical Center (2016-0862). The requirement for informed consent from individual patients was waived because of the retrospective nature of the study design.

\section{Surgical Procedures}

The conventional surgical approaches included median sternotomy $(\mathrm{n}=1053)$ or right thoracotomy approach $(\mathrm{n}=176)$ with longitudinal right-sided left atriotomy and transverse right atriotomy. In general, normal or mild hypothermic $\left(28^{\circ} \mathrm{C}-36^{\circ} \mathrm{C}\right)$ cardiopulmonary bypass was used, and myocardial protection was achieved with cold or tepid blood cardioplegia, del Nido solution, or a single shot of cold crystalloid cardioplegia using histidine-tryptophan-ketoglutarate solution per the attending surgeons' preferences.

From 1997 to 2001, the most commonly performed method for surgical AF ablation was the modified Cox-Maze III procedure using the cut-andsew technique. From 2001 to 2005, liquid nitrogen-based cryo-ablation (Frigitronics Cardiac Cryosurgical System 200; Frigitronics, Inc, Coopersurgical, Shelton, Conn) was applied at approximately $-70^{\circ} \mathrm{C}$ as a modified version of the Cox-Maze III procedure. After 2005, the modified procedure was performed using an argon-based cryo-ablation system with the Cardioblate Cryoflex probe (The Cardioblate CryoFlex Argonpowered Cryoablation System, Medtronic USA, Minneapolis, Minn) at approximately $-120^{\circ} \mathrm{C}$. From 2004 to 2008 , the microwave energy transfer method was applied for the limited cases $(n=67)$ using FLEX 4 microwave ablation probes (Afx Inc, Fremont, Calif).

The lesion set creations for the modified Cox-Maze III procedure have been described previously. ${ }^{7}$ Among the patients in the ablation group, 203 $(25.0 \%)$ underwent a confined left-side ablation procedure depending on the projected risks of ablation failure. For patients with a high risk of ablation failure, the bilateral ablation procedure was preferentially performed. The left atrial (LA) size was reduced for 537 patients $(66.1 \%)$ by resecting between the right inferior pulmonary vein and the posterior MV annulus, remaining narrower than $4 \mathrm{~cm}$ to prevent macro-reentry. The purpose of this procedure was to block the re-entry electronic signal. According to the previous study suggesting that LA appendage preservation resulted in superior LA contractile function, ${ }^{14}$ LA appendage resection was performed in approximately half of all patients (392/812, 48.3\%) depending on the presence of thrombi, the presentation of fine $\mathrm{AF}$, or a large LA appendage.

The MV repair or replacement techniques were the same as those described previously. ${ }^{12}$ In brief, patients with severe involvement of fibrosis to the MV were not regarded as fair candidate for repair. For those who were chosen to undergo MV replacement, patients chose their own prosthetic type after they were fully informed regarding the risks and benefits of undergoing the procedure primarily based on their age and comorbidities.

\section{Postoperative Managements}

For patients who underwent mechanical MV replacement, anticoagulation with warfarin was performed to maintain a target international normalized ratio of 2.0 to 3.0 after surgery in the light of reported higher incidence of intracranial hemorrhage in Asians compared with Westerners, ${ }^{15}$ including those patients with restored postoperative sinus rhythm. For patients who underwent MV repair or biological MV implantation, warfarin was administered with a target international normalized ratio of 1.5 to 2.5 for 3 to 6 months. Thereafter, the continuation of anticoagulation therapy was determined on the basis of the presence of risk factors for thromboembolism, such as a patient's age, history of cerebrovascular disease, rhythm status, and presence of atrial kicking. ${ }^{16}$ Regardless of whether surgical ablation was performed or not, patients with persistent postoperative AF continued anticoagulation therapy until sinus rhythm was restored. The presence of effective atrial contraction has been another factor in determining the continuation of anticoagulation therapy.

The rhythm status of the patients was verified by a follow-up 12-lead electrocardiogram at approximately $3,6,12,18$, and 24 months postoperatively and every year thereafter. For patients who were considered to have a restored sinus rhythm, 24-hour Holter monitoring was performed to evaluate the undetected AF by stat electrocardiogram with or without symptoms suggestive of arrhythmia. Patients who displayed any 1 of 3 
TABLE 1. Baseline characteristics

\begin{tabular}{|c|c|c|c|c|c|c|c|c|}
\hline & \multicolumn{4}{|c|}{ Overall cohort } & \multicolumn{4}{|c|}{ IPTW } \\
\hline & $\begin{array}{c}\text { Ablation } \\
(\mathbf{N}=\mathbf{8 1 2})\end{array}$ & $\begin{array}{l}\text { No ablation } \\
(N=417)\end{array}$ & $P$ value & SMD & Ablation & No ablation & $P$ value & SMD \\
\hline \multicolumn{9}{|l|}{ Characteristics } \\
\hline Age, y & $53.6 \pm 11.7$ & $56.1 \pm 11.3$ & $<.001$ & 11.33 & $54.6 \pm 11.4$ & $55.8 \pm 11.9$ & .23 & 0.109 \\
\hline Female gender, $\mathrm{n}(\%)$ & $577(71.1)$ & $261(62.6)$ & $<.001$ & 0.485 & $554.9(68.3)$ & $266.2(68.9)$ & .88 & 0.013 \\
\hline Hemoglobin, g/dL & $13.3 \pm 1.8$ & $12.7 \pm 2.0$ & $<.001$ & 2.014 & $13.2 \pm 1.80$ & $12.9 \pm 2.0$ & .25 & 0.107 \\
\hline Glomerular filtration rates, $\%$ & $80.8 \pm 21.1$ & $77.6 \pm 25.7$ & .03 & 25.72 & $79.9 \pm 21.5$ & $78.2 \pm 24.2$ & .35 & 0.076 \\
\hline Diabetes mellitus, $\mathrm{n}(\%)$ & $103(12.7)$ & $42(10.1)$ & .21 & 0.301 & $106.9(13.2)$ & $59.3(15.4)$ & .53 & 0.063 \\
\hline Hypertension, n (\%) & $161(19.8)$ & $87(20.9)$ & .72 & 0.407 & $178.8(22.0)$ & $89.5(23.2)$ & .76 & 0.028 \\
\hline ESRD, n $(\%)$ & $9(1.1)$ & $11(2.6)$ & .08 & 0.161 & $12.7(1.6)$ & $7.9(2.1)$ & .64 & 0.036 \\
\hline COPD, n (\%) & $24(3.0)$ & $15(3.6)$ & .66 & 0.186 & $24.7(3.0)$ & $9.7(2.5)$ & .59 & 0.032 \\
\hline Dyslipidemia, n (\%) & $37(4.6)$ & $12(2.9)$ & .20 & 0.167 & $35.3(4.3)$ & $27.0(7.0)$ & .32 & 0.115 \\
\hline PAOD, $n(\%)$ & $1(0.1)$ & $0(0)$ & $>.99$ & 0.072 & $0.9(0.1)$ & 0 & .49 & 0.047 \\
\hline Cerebrovascular disease, $\mathrm{n}(\%)$ & $19(2.3)$ & $24(5.8)$ & .003 & 0.233 & $19.1(2.4)$ & $10.5(2.7)$ & .66 & 0.023 \\
\hline \multicolumn{9}{|l|}{ Echocardiographic data } \\
\hline MV diagnosis, $\mathrm{n}(\%)$ & & & .06 & 0.389 & & & .99 & 0.002 \\
\hline Predominant mitral regurgitation & $189(23.3)$ & $76(18.2)$ & & & $184.7(22.7)$ & $86.8(22.5)$ & & \\
\hline Predominant mitral stenosis & $340(41.9)$ & $200(48.0)$ & & & $347.8(42.8)$ & $168.4(43.6)$ & & \\
\hline Combined & $283(34.9)$ & $141(33.8)$ & & & $279.5(34.4)$ & $131.1(33.9)$ & & \\
\hline Mitral regurgitation grade, $\mathrm{n}(\%)$ & & & .01 & 1.572 & & & .20 & 0.014 \\
\hline None & $202(24.9)$ & $94(22.5)$ & & & $196.9(24.2)$ & $73.6(19.1)$ & & \\
\hline Mild & $128(15.8)$ & $99(23.7)$ & & & $136.7(16.8)$ & $94.9(24.6)$ & & \\
\hline Moderate & $199(24.5)$ & $98(23.5)$ & & & $199.1(24.5)$ & $94.3(24.4)$ & & \\
\hline Severe & $283(34.9)$ & $126(30.2)$ & & & $279.3(34.4)$ & $123.4(31.9)$ & & \\
\hline Severe TR, n $(\%)$ & $353(43.5)$ & $201(48.2)$ & .13 & 0.500 & $370.1(45.6)$ & $183.4(47.5)$ & .66 & 0.038 \\
\hline LA dimension $>60 \mathrm{~mm}, \mathrm{n}(\%)$ & $298(36.7)$ & $244(58.5)$ & $<.001$ & 0.493 & $354.8(43.7)$ & $183.6(47.5)$ & .37 & 0.077 \\
\hline LA thrombi, $\%$ & $127(15.6)$ & $98(23.5)$ & .001 & 0.425 & $141.2(17.4)$ & $68.9(17.9)$ & .87 & 0.012 \\
\hline LV ejection fraction $<50 \%, \mathrm{n}(\%)$ & $236(29.1)$ & $127(30.5)$ & .66 & 0.461 & $246.1(30.3)$ & $113.8(29.5)$ & .83 & 0.018 \\
\hline MV area $<1 \mathrm{~cm}^{2}, \mathrm{n}(\%)$ & $211(26.0)$ & $100(24.0)$ & .49 & 0.428 & $213.5(26.3)$ & $101.3(26.2)$ & .99 & 0.002 \\
\hline Systolic PAP $>50 \mathrm{~mm} \mathrm{Hg}, \mathrm{n}(\%)$ & $110(13.5)$ & $98(23.5)$ & $<.001$ & 0.426 & $139.6(17.2)$ & $65.7(17.0)$ & .95 & 0.005 \\
\hline
\end{tabular}

$I P T W$, Inverse probability of treatment weighting; $S M D$, standardized mean difference; $E S R D$, end-stage renal disease; $C O P D$, chronic obstructive pulmonary disease; $P A O D$, peripheral arterial obstructive disease; $M V$, mitral valve; $T R$, tricuspid regurgitation; $L A$, left atrial; $L V$, left ventricular; $P A P$, pulmonary arterial pressure.

potential AF rhythms (AF, atrial flutter, or atrial tachycardia lasting $>30$ seconds) on Holter monitoring were regarded as having $\mathrm{AF}$ recurrence. ${ }^{17}$

Patients who were considered as having AF recurrence after surgical ablation were mostly treated with class I/III antiarrhythmic medications or electrical cardioversion to restore sinus rhythm. For patients with $\mathrm{AF}$ that persisted after these treatments, beta-blockers, calcium-channel blockers, or digitalis along with continued anticoagulation therapy was prescribed.

\section{Statistical Analyses}

Categoric variables, presented as frequencies and percentages, were compared using the chi-square test or Fisher exact test. Continuous variables, expressed as the mean \pm standard deviation or median with range, were compared using Student unpaired $t$ tests (between 2 groups) or 1 -way analysis of variance tests (among 3 groups), as appropriate. Conditional logistic regression analysis was performed for the evaluation of the early outcomes, and the Cox proportional hazard regression model was used in the evaluation of the late time-related outcomes (death, valverelated complications, and postoperative rhythm outcomes). To assess the rhythm outcomes, the time lag from the hospital discharge to the time of electrocardiograms was incorporated into the Cox models. Longitudinal mixed-effects model was used to address intra-individual correlation of repeated measurements during the comparison of the prevalence of postoperative AF. Kaplan-Meier analyses were used to assess the conditional probability of survival or freedom from valve-related complications using "survplot" package, and log-rank tests were used to compare inter-group differences. Mortality was regarded as a competing event to evaluate valve-related outcomes using competing risk analysis. Thromboembolic events were evaluated to determine the influence on overall mortality using time-varying Cox models.

To reduce the impact of treatment-selection bias and potential confounders in the comparison of outcomes between the ablation and no ablation groups, we adjusted the differences in the patient's baseline variables with an inverse probability of treatment weighting (IPTW) method derived from the propensity score (PS) ${ }^{18}$ Those variables are listed with the values of standardized mean differences (SMDs) in the right columns of Tables 1 and 2. The weight of the patient receiving MV surgery with AF ablation was the inverse of the PS, whereas the weight of the patient receiving MV surgery alone was the inverse of " 1 minus the patient's PS" for IPTW techniques. A weighted logistic regression model and weighted Cox proportional hazards model were used for IPTW analyses on clinical outcomes. Cox-proportional hazard models were used with robust standard errors. The validity of the proportional hazards assumption was tested using scaled Schoenfeld residuals from the Cox model on parametric models, and no relevant violations were found. The PS was estimated by the logistic regression model incorporating the 42 baseline variables, including baseline characteristics, inter-quintile surgical periods, and concomitant surgical procedures (Tables E1 and E2). 
TABLE 2. Surgical periods and procedures in the ablation and no ablation groups

\begin{tabular}{|c|c|c|c|c|c|c|c|c|}
\hline & \multicolumn{4}{|c|}{ Overall cohort } & \multicolumn{4}{|c|}{ IPTW } \\
\hline & $\begin{array}{c}\text { Ablation } \\
(\mathbf{N}=\mathbf{8 1 2})\end{array}$ & $\begin{array}{l}\text { No ablation } \\
(\mathrm{N}=417)\end{array}$ & $P$ value & SMD & Ablation & No ablation & $P$ value & SMD \\
\hline \multicolumn{9}{|l|}{ Operations } \\
\hline Years at operation & & & $<.001$ & 0.457 & & & .97 & 0.017 \\
\hline Quintile range $1(1997-2001, \mathrm{n}=245)$ & $114(14.0)$ & $131(31.4)$ & & & $137.0(16.9)$ & $59.7(15.5)$ & & \\
\hline Quintile range $2(2002-2005, \mathrm{n}=245)$ & $133(16.4)$ & $113(27.1)$ & & & $167.0(20.6)$ & $80.4(20.8)$ & & \\
\hline Quintile range $3(2005-2008, \mathrm{n}=245)$ & $163(20.1)$ & $83(19.9)$ & & & $174.7(21.5)$ & $89.7(23.2)$ & & \\
\hline Quintile range $4(2008-2012, \mathrm{n}=245)$ & $194(23.9)$ & $52(12.5)$ & & & $165.5(20.4)$ & $75.2(19.5)$ & & \\
\hline Quintile range $5(2012-2016, \mathrm{n}=249)$ & $208(25.6)$ & $38(9.1)$ & & & $167.8(20.7)$ & $81.2(21.0)$ & & \\
\hline MV procedures & & & $<.001$ & 0.398 & & & .60 & 0.049 \\
\hline Valve repair procedure & $143(17.6)$ & $18(4.3)$ & & & $108.1(13.3)$ & $39.1(10.1)$ & & \\
\hline Mechanical valve replacement & $507(62.4)$ & $322(77.2)$ & & & $543.0(66.9)$ & $272.3(70.5)$ & & \\
\hline Bioprosthetic valve replacement & $162(20.0)$ & $77(18.5)$ & & & $160.9(19.8)$ & $74.8(19.4)$ & & \\
\hline \multicolumn{9}{|l|}{ Combined procedures } \\
\hline Atrial septal defect closure & $21(2.6)$ & $7(1.7)$ & .42 & 0.129 & $20.6(2.5)$ & $9.1(2.4)$ & .89 & 0.011 \\
\hline Tricuspid valve plasty, n (\%) & $435(53.6)$ & $202(48.4)$ & .10 & 0.500 & $433.3(53.4)$ & $208.1(53.9)$ & .91 & 0.010 \\
\hline Aortic valve replacement, $\mathrm{n}(\%)$ & $219(27.0)$ & 137 (32.9) & .04 & 0.470 & $228.7(28.2)$ & $127.7(33.1)$ & .22 & 0.106 \\
\hline CABG, $n(\%)$ & $36(4.4)$ & $16(3.8)$ & .73 & 0.192 & $44.4(5.5)$ & $27.5(7.1)$ & .46 & 0.069 \\
\hline Aortic procedures, $\mathrm{n}(\%)$ & $41(5.0)$ & $5(1.2)$ & .001 & 0.109 & $32.0(3.9)$ & $17.7(4.6)$ & .77 & 0.032 \\
\hline
\end{tabular}

$I P T W$, Inverse probability of treatment weighting; $S M D$, standardized mean difference; $M V$, mitral valve; $C A B G$, coronary artery bypass grafting.

Discrimination and calibration of the PS were assessed with HosmerLemeshow statistics and C statistics (Table E3). PS matching was processed on the basis of the logit of the PS using calipers of width 0.10 or less of the standard deviation. Fit-proportional hazards regression models were used for the risk analyses in the PS-matched cohort. Stroke was regarded as a time-varying risk to evaluate the effect on long-term mortality.

In the subgroup analyses, the impact of the addition of AF ablation was evaluated separately according to the type of MV procedure (repair, mechanical prosthetic replacement, and bioprosthetic prosthetic replacement). After adjusting the baseline characteristics using individualized IPTW methodology based on PS, weighted risk analyses for clinical outcomes were conducted for the repair, mechanical, or bioprosthetic MV replacement subgroups.

$\mathrm{R}$ statistical software version 3.3.1, SPSS software version 12 (SPSS Inc, an IBM Company, Chicago, Ill), and SAS software version 9.1 (SAS Institute, Inc, Cary, NC) were used for statistical analyses. All reported $P$ values were 2-tailed.

\section{Postoperative Rhythm Outcomes}

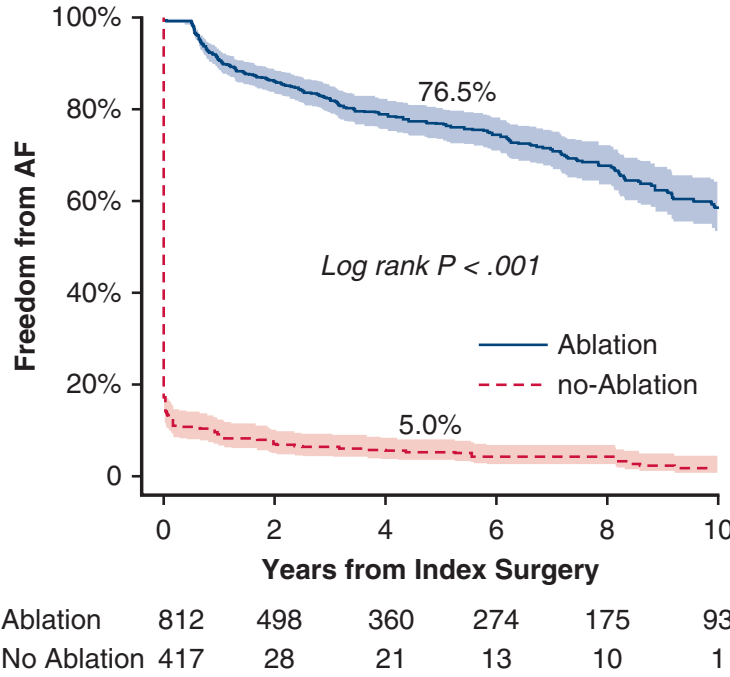

A

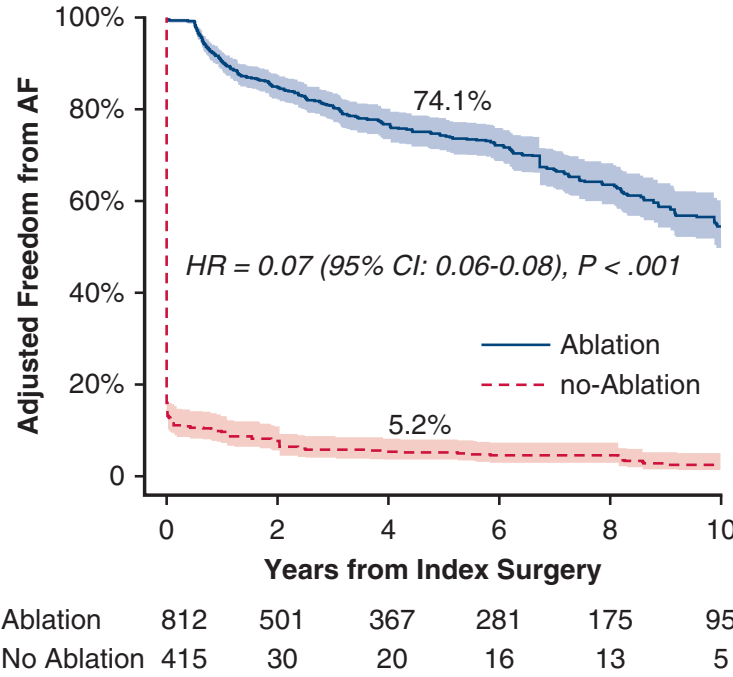

B

FIGURE 1. Postoperative rhythm outcomes in the ablation and no ablation groups. Solid blue line = ablation group; dashed red line = no ablation group. A, Unadjusted Kaplan-Meier plot for freedom from AF. B, Adjusted Kaplan-Meier plot for freedom from AF. AF, Atrial fibrillation; HR, hazard ratio; $C I$, confidence interval. 
TABLE 3. Crude risk analyses for adverse clinical outcomes: Ablation group versus no ablation group

\begin{tabular}{|c|c|c|c|c|}
\hline & \multicolumn{4}{|c|}{ All cohort $(n=1229)$} \\
\hline & Ablation & No ablation & HR $(95 \% \text { CI })^{*}$ & $P$ value \\
\hline Adverse clinical outcomes & $\mathrm{n}=812$ & $\mathrm{n}=417$ & & \\
\hline Early mortality, n (\%) & $10(1.2)$ & $10(2.4)$ & $0.51(0.21-1.25)$ & .13 \\
\hline Composite of primary outcomes, $\mathrm{n}(\% / \mathrm{PY}) \dagger$ & $111(2.7)$ & $136(5.0)$ & $0.56(0.44-0.73)$ & $<.001$ \\
\hline Overall mortality, n (\%/PY) & $83(2.0)$ & $119(4.1)$ & $0.52(0.39-0.69)$ & $<.001$ \\
\hline Thromboembolic events, $\mathrm{n}(\% / \mathrm{PY})$ & $35(0.9)$ & $31(1.1)$ & $0.72(0.45-1.17)$ & .18 \\
\hline Composite of valve-related complications, $\mathrm{n}(\% / \mathrm{PY}) \ddagger$ & $87(2.2)$ & $76(3.0)$ & $0.75(0.55-1.02)$ & .07 \\
\hline Reoperation & $14(0.3)$ & $14(0.5)$ & $0.76(0.34-1.69)$ & .49 \\
\hline Hemorrhagic events & $36(0.9)$ & $38(1.4)$ & $0.67(0.42-1.06)$ & .09 \\
\hline Infective endocarditis & $10(0.2)$ & $8(0.3)$ & $0.86(0.35-2.14)$ & .75 \\
\hline \multicolumn{5}{|l|}{ Rhythm outcomes, n (\%/PY) } \\
\hline Postoperative AF occurrence & $218(6.1)$ & $389(29.0)$ & $0.06(0.05-0.07)$ & $<.001$ \\
\hline Catheter ablation & $3(0.1)$ & $3(0.1)$ & $0.73(0.15-3.66)$ & .71 \\
\hline Pacemaker insertion & $38(0.9)$ & $8(0.3)$ & $3.24(1.5-6.99)$ & .003 \\
\hline
\end{tabular}

$H R$, Hazard ratio; $C I$, confidence interval; $P Y$, patient-year; $A F$, atrial fibrillation. *Odds ratios for early mortality and HRs for other outcomes (results of no ablation group are references). $\dagger$ The composite of primary outcomes includes mortality and thromboembolic outcomes. $\ddagger$ The composite outcome of valve-related complications includes reoperation of the MV, thromboembolic events, anticoagulation-related bleeding complications, and infective endocarditis.

\section{RESULTS}

\section{Baseline Characteristics}

The mean patient age was $54.4 \pm 11.7$ years, and 838 $(68.2 \%)$ were female. The baseline demographics and clinical profiles of the patients are listed in Table 1. Female sex and predominant regurgitation mode of MV pathology were more common in the ablation group than in the no ablation group $(P<.001)$. The patients in the ablation group were younger $(P<.001)$, and they had lower blood creatinine levels $(P=.03)$ and larger LA diameters $(P<.001)$.

\section{Unadjusted Clinical Outcomes}

The early death rates were $1.2 \%(n=10 / 812)$ in the ablation group and $2.4 \%(\mathrm{n}=10 / 417)$ in the no ablation group $(P=.13)$. The differences in the rates of early major morbidities were not statistically significant between the 2 groups (Table E4).

Figure 1, $A$, depicts freedom from the first AF occurrence in the ablation and no ablation groups. Freedom from the first $\mathrm{AF}$ occurrence at 5 years was $76.5 \% \pm 1.8 \%$ and $4.5 \% \pm 1.0 \%$ in the ablation and no ablation groups, respectively $(P<.001)$. The patients with $\mathrm{AF}$ at immediate and 3, 6, and 9 years after surgery are listed in Table E5.

During a median follow-up of 62.5 (interquartile range [IQR], 20.0-110.9) months, 83 (2.0\% per patient-year [PY] $)$ and $119(4.1 \% / \mathrm{PY})$ patients died, and $35(0.9 \% /$ $\mathrm{PY})$ and $31(1.1 \% / \mathrm{PY})$ thromboembolic events occurred in the ablation and no ablation groups, respectively (Table 3). When unadjusted, patients who underwent concomitant surgical AF ablation showed a significantly lower risk of overall mortality compared with those who underwent MV surgery alone (hazard ratio [HR], 0.52; 95\% confidence interval $[\mathrm{CI}], 0.39-0.69 ; P<.001)$. The risk for thromboembolic events tended to be lower in the ablation group, although this was not statistically significant (HR, $0.72 ; 95 \%$ CI, $0.45-1.17 ; P=.18$ ). The risk of composite of mortality and thromboembolic events was significantly lower in the ablation group (HR, $0.56 ; 95 \% \mathrm{CI}$, $0.44-0.73 ; P<.001)$. However, the patients in the ablation group had a higher risk for permanent pacemaker insertion $(0.9 \%$ vs $0.3 \%, P=.003)$.

Figure 2, A, depicts the unadjusted Kaplan-Meier plots for survival; Figure 2, $B$, depicts freedom from thromboembolic complications; and Figure 2, $C$, depicts the composite of mortality and thromboembolic events. Overall survival at 10 years was $83.2 \% \pm 2.0 \%$ and $75.0 \% \pm 2.5 \%$ in the ablation and no ablation groups, respectively $(P<.001)$. Freedom from thromboembolic events at 10 years was $92.4 \% \pm 1.4 \%$ and $89.3 \% \pm 2.0 \%$ in the ablation and no ablation groups, respectively $(P=.18)$. Freedom from the composite of valve-related events at 10 years was $81.7 \% \pm 2.2 \%$ and $77.4 \% \pm 2.6 \%$ in the ablation and no ablation groups, respectively (Figure E1, $A$ ).

\section{Adjusted Clinical Outcomes}

The main PS model showed reasonable discrimination and calibration profiles (Table E3). IPTW methodology was used on the basis of the PS for the adjustment of the patients in the ablation and no ablation groups, and the SMD of nearly all of these factors was within 0.1 , thereby indicating reasonable weighting (Tables 1 and 2).

Postoperative rhythm outcomes after baseline adjustment remained similar to the concomitant $\mathrm{AF}$ ablation, which resulted in a significantly lower rate of freedom from the first AF occurrence (HR, 0.08; 95\% CI, 0.07-0.09; $P<.001$, Figure $1, B$ ) but with a higher rate of pacemaker insertion (HR, 5.34; 95\% CI, 1.98-14.4; $P<.001$ ).

Table 4 summarizes the weighted odds ratio and HR for the clinical outcomes between the ablation and no ablation 


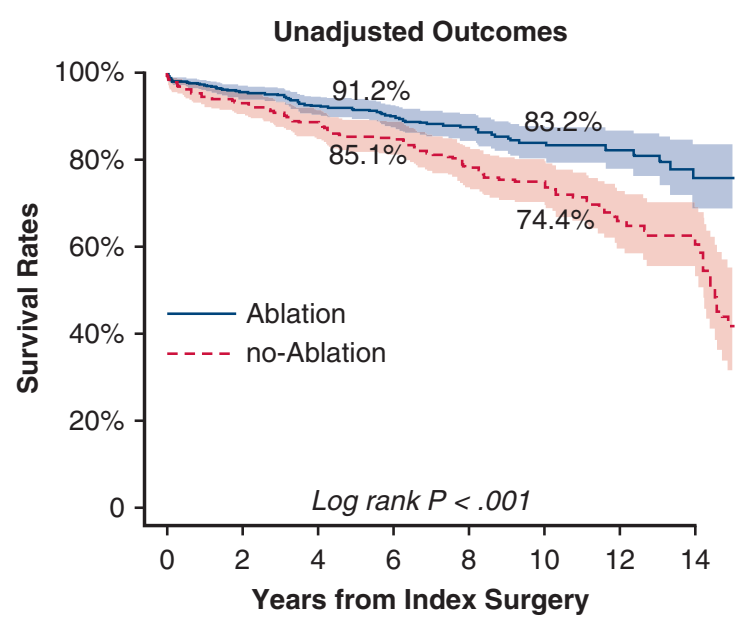

$\begin{array}{lllllllll}\text { Ablation } & 812 & 554 & 426 & 330 & 225 & 132 & 77 & 36\end{array}$

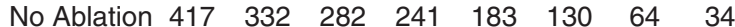
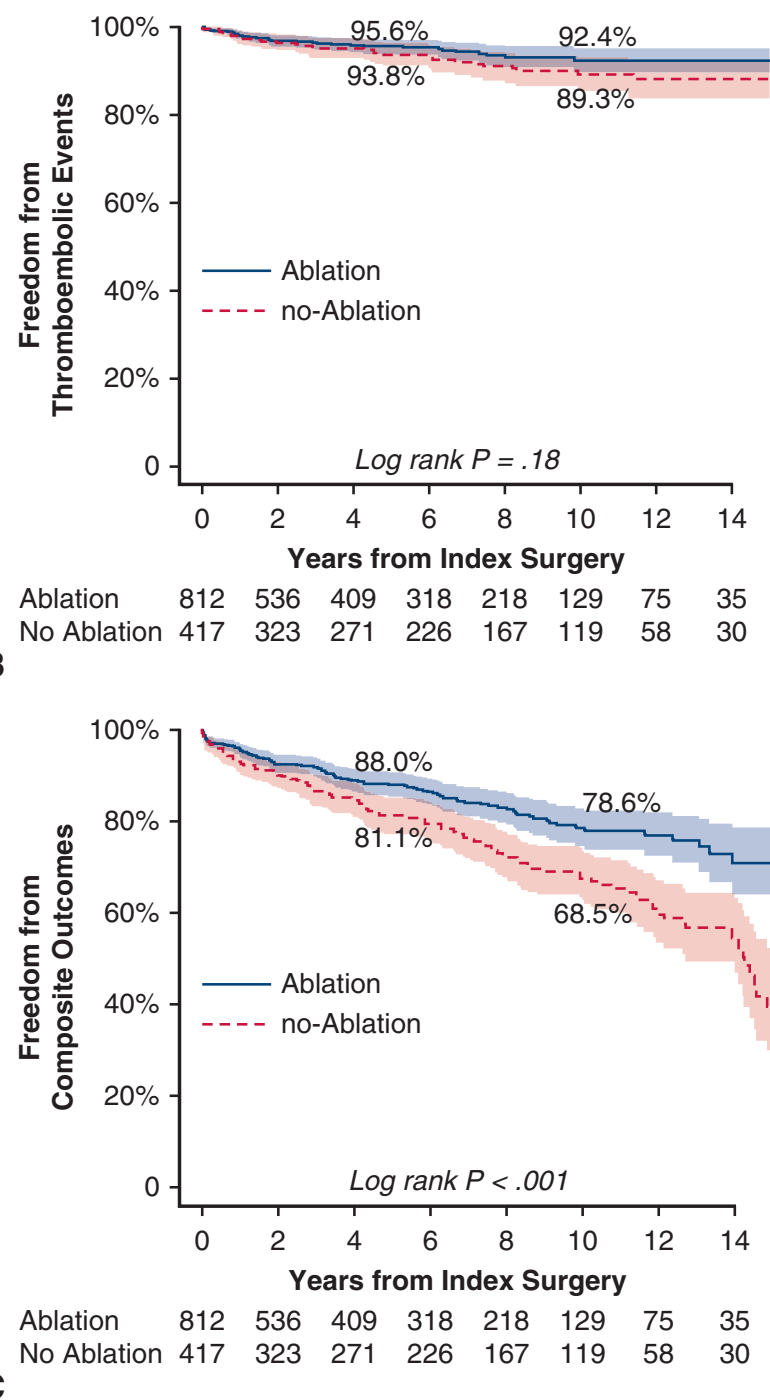

FIGURE 2. Unadjusted Kaplan-Meier plots for clinical outcomes. Solid blue line = ablation group; dashed red line $=$ no ablation group. A, groups. A weighted risk analysis for early death showed no significant statistical difference between the ablation and no ablation groups $(P=.45)$. The addition of AF ablation during rheumatic MV surgery significantly decreased the risks for overall mortality (HR, $0.69 ; 95 \%$ CI, $0.52-0.93$; $P=.02$ ), thromboembolic events (HR, 0.49; 95\% CI, $0.32-0.76 ; P=.001$ ), and the composite of both (HR, $0.61 ; 95 \%$ CI, $0.48-0.79 ; P<.001)$ in adjusted analyses. Figure 3, A, depicts weighted Kaplan-Meier plots of survival; Figure 3, $B$, depicts freedom from thromboembolic complication; and Figure 3, $C$, depicts the composite of mortality and thromboembolic events. After weighting, the freedom from the composite of valve-related events at 10 years was $78.5 \% \pm 2.2 \%$ and $72.4 \% \pm 3.2 \%$ in the ablation and no ablation groups, respectively (Figure E1, B).

For further verification of the results from the weighted analyses using the IPTW method, the same analyses were performed in the PS-matched cohort. By using PSmatching methodology, 265 pairs of patients were identified as being well balanced for most baseline covariates (Table E1). After adjustment, 21 patients (7.9\%), 189 patients $(71.3 \%)$, and 55 patients $(20.8 \%)$ in the ablation group and 17 patients $(6.4 \%), 190$ patients $(71.7 \%)$, and 58 patients $(21.9 \%)$ in the no ablation group had undergone repair, mechanical replacement, and bioprosthetic replacement, respectively. The results of the risk analyses on clinical outcomes after PS matching were similar to the results before PS matching (Table E6).

\section{Thromboembolic Events}

Among 66 thromboembolic events after rheumatic MV surgery, $46(69.7 \%)$ were stroke (Table E7). Among them, 33 patients had a middle cerebral artery infarction, as indicated by brain magnetic resonance imaging, which resulted in hemiparesis. Neurologic symptoms disappeared within 1 month in $21.2 \%(14 / 66)$ of the patients by immediate thrombolytic or continuous anticoagulation therapies.

Twenty-one $(0.30 \% / \mathrm{PY})$ deaths occurred among patients who experienced thromboembolic events. Seven patients $(0.17 \% / \mathrm{PY})$ and 14 patients $(0.49 \% / \mathrm{PY})$ died after thromboembolic events in the ablation and no ablation groups, respectively. Time-varying Cox analysis revealed that the occurrence of thromboembolic events after rheumatic MV surgery was significantly associated with an increased risk of mortality (HR, 3.08; 95\% CI, 1.92-4.93; $P<.001$ ). More specifically, the occurrence of stroke was a significant risk factor for death (HR, 3.97; 95\% CI, 2.36-6.69; $P<.001)$.

Kaplan-Meier plot for survival. B, Kaplan-Meier plot for freedom from thromboembolic event rates. C, Kaplan-Meier plot for freedom from composite outcomes of mortality and valve-related events. 
TABLE 4. Weighted risk analyses for adverse clinical outcomes: Ablation group versus no ablation group

\begin{tabular}{|c|c|c|c|c|}
\hline & \multicolumn{4}{|c|}{ IPTW } \\
\hline & Ablation & No ablation & HR $(95 \% \text { CI })^{*}$ & $P$ value \\
\hline \multicolumn{5}{|l|}{ Adverse clinical outcomes } \\
\hline Early mortality, n (\%) & $12.6(1.5)$ & $8.3(2.2)$ & $0.93(0.76-1.13)$ & .45 \\
\hline Composite of primary outcomes, $\mathrm{n}(\% / \mathrm{PY}) \dagger$ & $139.6(17.2)$ & $107.3(27.8)$ & $0.61(0.48-0.79)$ & $<.001$ \\
\hline Overall mortality, n (\%/PY) & $106.0(13.0)$ & $77.1(20.0)$ & $0.69(0.52-0.93)$ & .02 \\
\hline Thromboembolic events, $\mathrm{n}(\% / \mathrm{PY})$ & $41.6(5.1)$ & $40.5(10.5)$ & $0.49(0.32-0.76)$ & .001 \\
\hline Composite of valve-related complications, $\mathrm{n}(\% / \mathrm{PY}) \ddagger$ & $108.8(13.4)$ & $69.5(18.0)$ & $0.75(0.55-1.01)$ & .06 \\
\hline Reoperation & $13.1(1.6)$ & $7.9(2.0)$ & $0.89(0.36-2.22)$ & .80 \\
\hline Hemorrhagic events & $53.8(6.6)$ & $26.4(6.8)$ & $1.07(0.67-1.72)$ & .76 \\
\hline Infective endocarditis & $8.7(1.1)$ & $4.5(1.2)$ & $0.95(0.31-2.95)$ & .93 \\
\hline \multicolumn{5}{|l|}{ Rhythm outcomes, n (\%/PY) } \\
\hline Postoperative AF occurrence & $244.1(30.1)$ & $397.6(95.8)$ & $0.07(0.06-0.08)$ & $<.001$ \\
\hline Catheter ablation & $2.3(0.3)$ & $3.1(0.8)$ & $0.37(0.07-2.05)$ & .25 \\
\hline Pacemaker insertion & $45.4(5.6)$ & $4.3(1.1)$ & $5.34(1.98-14.4)$ & $<.001$ \\
\hline
\end{tabular}

$I P T W$, Inverse probability of treatment weighting; $H R$, hazard ratio; $C I$, confidence interval; $P Y$, patient-year; $A F$, atrial fibrillation. *Odds ratios for early mortality and HRs for other outcomes (results of the no ablation group are references). $\dagger$ The composite of primary outcomes includes mortality and thromboembolic outcomes. $\ddagger$ The composite outcome of valve-related complications includes reoperation of the MV, thromboembolic events, anticoagulation-related bleeding complications, and infective endocarditis.

\section{Subgroup Analyses: Repair, Mechanical, and Bioprostheses Groups}

The mean follow-up duration of the repair, mechanical, and bioprosthetic subgroups was 104.5 (IQR, 47.6-137.4), 56.8 (IQR, 18.1-110.3), and 51.1 (IQR, 18.2-91.3) months, respectively. Three separate PS-matching and IPTW analyses were performed on the repair, mechanical, and bioprosthetic subgroups. The values of SMD of baseline variables after weighting in each subgroup are listed in Table E3. After adjustments, the reduced risk in the composite of death and thromboembolic events remained similar in the mechanical $(\mathrm{n}=829$; HR, $0.53 ; 95 \% \mathrm{CI}$, $0.39-0.73$ ), bioprosthetic ( $\mathrm{n}=239$; HR, 0.67; 95\% CI, $0.41-1.08)$, and replacement and repair $(\mathrm{n}=161$; HR, $0.17 ; 95 \%$ CI, 0.06-0.52) subgroups (Table E8). No significant interaction between the addition of AF ablation and the types of MV surgery was observed ( $P$ for interaction $=.47$ ).

\section{DISCUSSION}

The present study evaluated the impacts of surgical ablation on clinical and postoperative rhythm outcomes in patients who underwent MV surgery for rheumatic heart disease. Effective sinus rhythm restoration and maintenance were significantly better in the ablation group than in the no ablation group. The addition of AF ablation was associated with lower risks of mortality and thromboembolic events (Figure 4). Additional analyses were conducted to define the sensitivity of the outcomes depending on unmeasured confounders, such as the surgery types and ablation energy sources. In the additional analyses, LA appendage resection $(P=.65$ and .85$)$, isolated LA ablation $(P=.50$ and .81$)$, cut-and-sew technique ( $P=.53$ and .16$)$, nitrogen cryoablation $(P=.42$ and .14$)$, and microwave ablation $(P=.51$ and .71) did not affect the mortality and stroke outcomes, respectively, in the ablation group (Table E9). The survival benefit and thromboembolic event-lowering effect by the addition of AF ablation remained similar in the repair, mechanical, and bioprosthetic MV replacement subgroup analyses.

Rheumatic valvular heart disease has been a major global problem, resulting in high incidence rates of disability and death. ${ }^{19,20}$ Patients with this disease face high risks of adverse progression to infective endocarditis and $\mathrm{AF}$, and these adverse outcomes are strongly responsible for stroke in advanced rheumatic heart disease. ${ }^{21}$ The annual incidence of stroke is up to $6 \%$ in patients with rheumatic valvular disease, with more than $90 \%$ of the events occurring in patients with $\mathrm{AF}^{22}$

To prevent stroke, the importance of sinus rhythm restoration for patients with $\mathrm{AF}$ who underwent degenerative MV surgery has been well demonstrated. ${ }^{23-25}$ Because surgical AF ablation has been demonstrated to be an effective method of restoring sinus rhythm, not undergoing surgical ablation has been known to be a significant risk factor for stroke. ${ }^{7,26}$ However, the efficacy of $\mathrm{AF}$ ablation in patients with rheumatic heart disease is believed to be worse than in those undergoing degenerative MV surgery. This is because the occurrence of $\mathrm{AF}$ in this disease is closely associated with continuous fibrosis on the MV apparatus and an enlarged left atrium. ${ }^{19,27,28}$ However, several recent studies have reported acceptable rhythm outcomes after AF ablation in the patients with rheumatic heart disease. ${ }^{29,30}$ For instance, Labin and colleagues $^{29}$ reported that the 


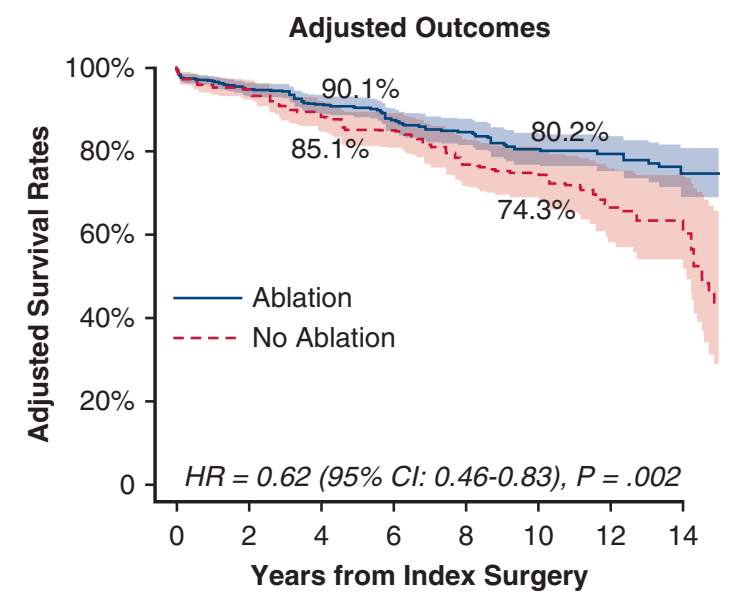

$\begin{array}{lllllllll}\text { Ablation } & 812 & 580 & 463 & 370 & 265 & 170 & 109 & 47\end{array}$

A

No Ablation $\begin{array}{llllllll}378 & 279 & 216 & 165 & 107 & 68 & 29 & 14\end{array}$

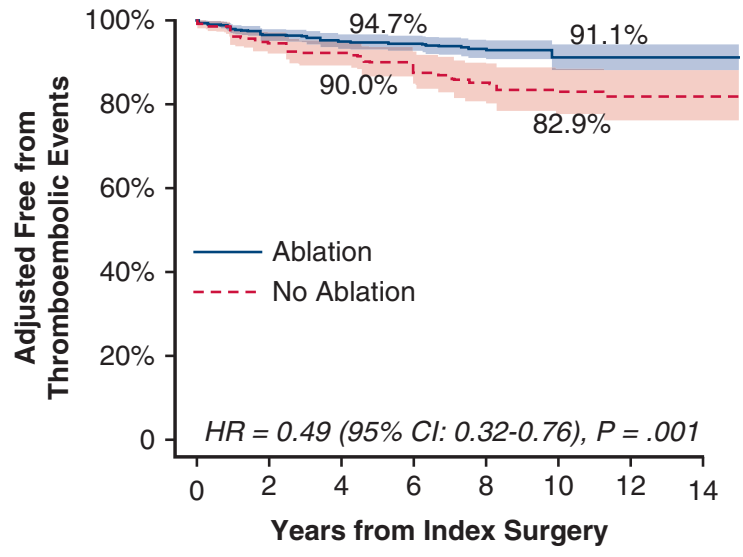

B

$\begin{array}{lllllllll}\text { Ablation } & 812 & 554 & 435 & 344 & 243 & 149 & 92 & 39\end{array}$

No Ablation $\begin{array}{llllllll}386 & 278 & 216 & 163 & 100 & 68 & 30 & 14\end{array}$

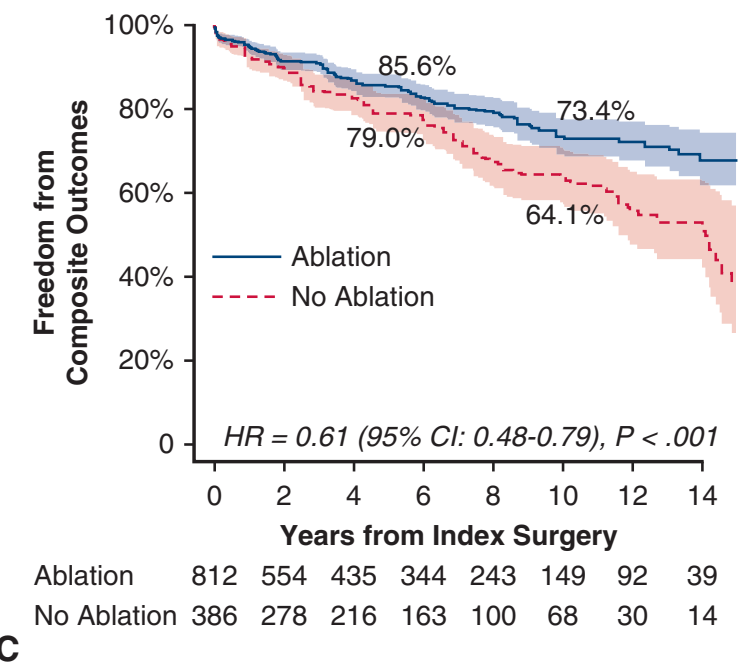

FIGURE 3. Adjusted Kaplan-Meier plots for clinical outcomes. Solid blue line $=$ ablation group; dashed red line $=$ no ablation group. A, Kaplan-Meier plot for survival. B, Kaplan-Meier plot for freedom from thromboembolic event rates. C, Kaplan-Meier plot for freedom from composite outcomes of mortality and valve-related events. $H R$, Hazard ratio; $C I$, confidence interval.
Cox-Maze IV procedure demonstrated long-term efficacy in restoring sinus rhythm among 92 patients with rheumatic MV disease, and this outcome was similar to that found in 153 patients with degenerative MV disease. ${ }^{31}$

To truly understand the benefit of adding AF ablation to rheumatic heart disease treatment, including AF ablation in treatment, this should be further demonstrated by directly comparing patients with rheumatic heart disease who underwent $\mathrm{AF}$ ablation with those who did not. In a recent randomized trial, the addition of surgical ablation for the patients with rheumatic MV disease resulted in improved freedom from stroke or death compared with MV surgery alone. ${ }^{32}$ In the cited study, the risk of the composite of death and stroke events was reduced by up to $75 \%$ by the addition of the cut-and-sew CoxMaze III procedure. However, the results from the cited study are difficult to generally accept because the clinical outcomes are limited to within 1 year. In addition, the huge gaps in hard end points, such as death and stroke, may be influenced by underpowered statistical analyses based on the small number of patients (total $\mathrm{N}=130$ ). Conversely, to the best of our knowledge, our study included the largest number of patients with the longest follow-up period for a comparison between the ablation and no ablation groups.

The mechanisms by which AF directly influences mortality in patients with MV disease and how surgical AF ablation confers survival benefits have been issues in previous investigations. ${ }^{32,33}$ In the present study, a thromboembolic event was significantly associated with ensuing death when these 2 factors were analyzed by the time-dependent Cox models. This finding indicates that the reduced risk of stroke by the addition of $\mathrm{AF}$ ablation may be the leading contributor of enhanced survival outcomes in this cohort, whereas the impact of other intermediary outcomes, such as AF-associated heart failure, on survival may need to be investigated further in future studies.

\section{Study Limitations}

This study is inherently limited by its retrospective and observational nature. Although we attempted to use rigorous statistical adjustment techniques, unmeasured residual biases may have influenced our results. Because the present study included a follow-up of approximately 20 years, several nonquantifiable parameters, such as surgical skills and various valve prostheses, may have affected the results and surgeon factor. The small number of patients in the repair and bioprosthetic subgroups may be responsible for the underpowered results of subgroup analyses. Finally, the results of this study may not be generalizable because they were derived from a large tertiary center in an endemic area of rheumatic MV disease; however, further 


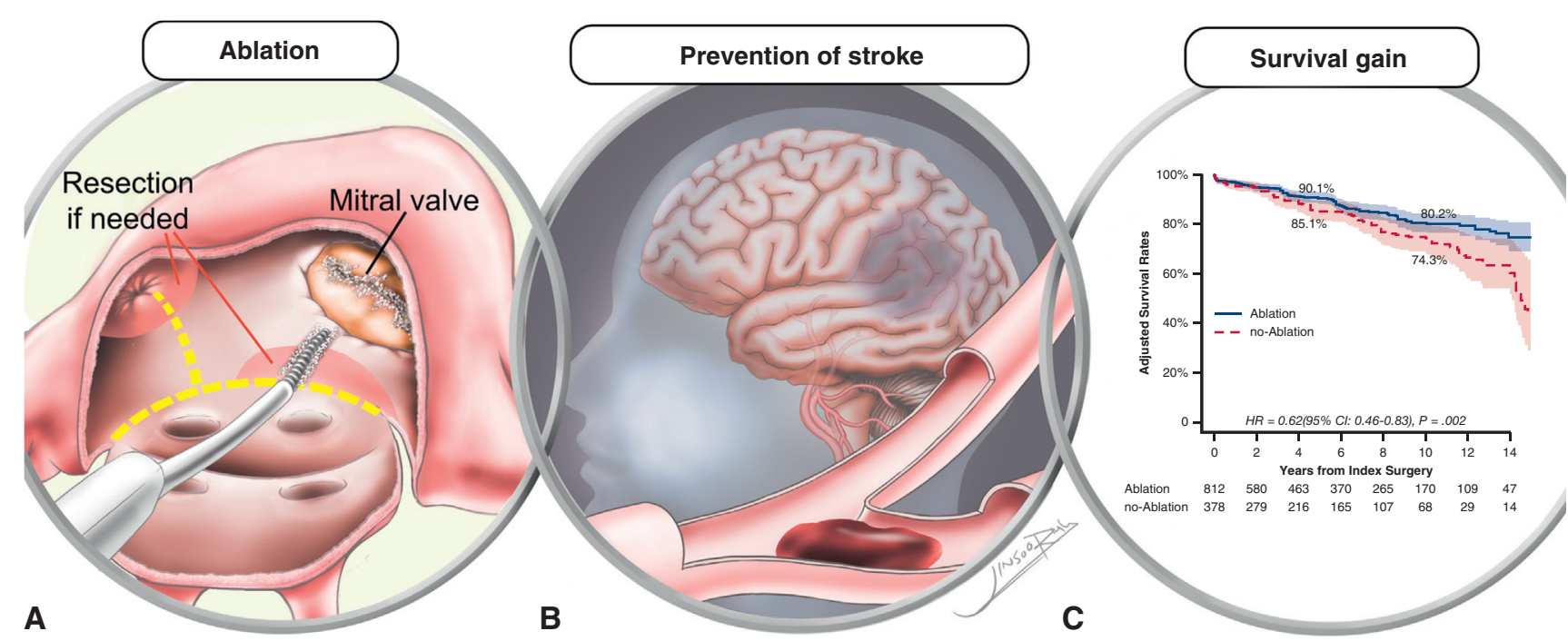

FIGURE 4. Survival benefit and stroke prevention by the addition of surgical AF ablation during the rheumatic MV surgery. A, Surgical ablation on left atrium by cryoablation is illustrated. For the patients with high risk of stroke, LA appendage and posterior wall resection procedures were combined. B, The addition of surgical ablation for the patients undergoing rheumatic MV surgery had a protective effect from thromboembolic events. C, Adjusted KaplanMeier plot for survival showed a beneficial effect by the addition of surgical AF ablation for the patients undergoing rheumatic MV surgery. $H R$, Hazard ratio; $C I$, confidence interval.

validation is needed, such as in a randomized controlled trial.

\section{CONCLUSIONS}

The addition of AF ablation for patients undergoing rheumatic MV surgery was found to be acceptably efficacious in restoring and maintaining sinus rhythm. In addition, surgical AF ablation was associated with lower mortality and thromboembolic event rates. Therefore, the addition of

\section{Baseline Profile Adjustments}

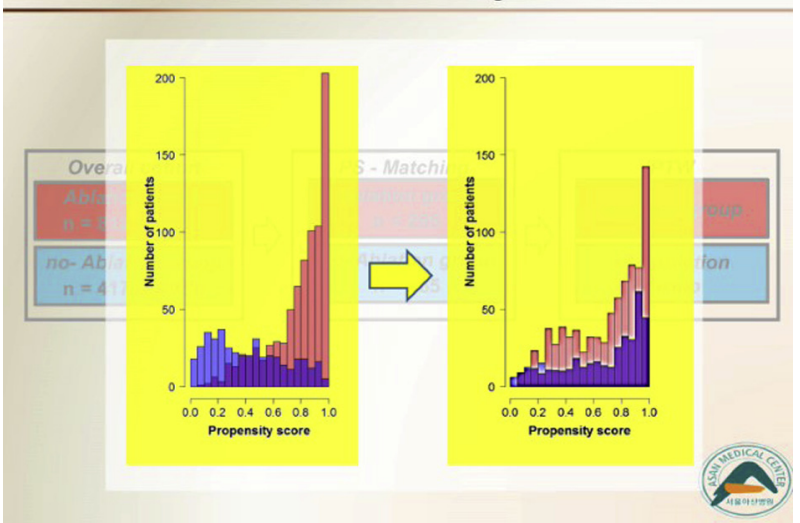

VIDEO 1. Video of the advantage of addition of atrial fibrillation ablation in the patients undergoing rheumatic mitral valve surgery. Video available at: https://www.jtcvs.org/article/S0022-5223(18)32524-8/fulltext. the AF ablation procedure during rheumatic MV surgery is a suitable treatment option (Video 1).

\section{Conflict of Interest Statement}

Authors have nothing to disclose with regard to commercial support.

\section{References}

1. Nishimura RA, Otto CM, Bonow RO, Carabello BA, Erwin JP, Fleisher LA, et al 2017 AHA/ACC focused update of the 2014 AHA/ACC guideline for the management of patients with valvular heart disease: a report of the American College of Cardiology/American Heart Association task force on clinical practice guidelines. Circulation. 2017;135:e1159-95.

2. Obadia JF, el Farra M, Bastien OH, Lievre M, Martelloni Y, Chassignolle JF. Outcome of atrial fibrillation after mitral valve repair. J Thorac Cardiovasc Surg. 1997;114:179-85.

3. Badhwar V, Rankin JS, Damiano RJ Jr, Gillinov AM, Bakaeen FG, Edgerton JR, et al. The Society of Thoracic Surgeons 2017 clinical practice guidelines for the surgical treatment of atrial fibrillation. Ann Thorac Surg. 2017;103:329-41.

4. Saint LL, Damiano RJ, Cuculich PS, Guthrie TJ, Moon MR, Munfakh NA, et al Incremental risk of the Cox-Maze IV procedure for patients with atrial fibrillation undergoing mitral valve surgery. J Thorac Cardiovasc Surg. 2013;146:1072-7.

5. Doukas G, Samani NJ, Alexiou C, Oc M, Chin DT, Stafford PG, et al. Left atrial radiofrequency ablation during mitral valve surgery for continuous atrial fibrillation: a randomized controlled trial. JAMA. 2005;294:2323-9.

6. Bando K, Kasegawa H, Okada Y, Kobayashi J, Kada A, Shimokawa T, et al. Impact of preoperative and postoperative atrial fibrillation on outcome after mitral valvuloplasty for nonischemic mitral regurgitation. J Thorac Cardiovasc Surg. 2005;129:1032-40.

7. Bum KJ, Suk MJ, Yun SC, Kee KW, Jung SH, Jung CS, et al. Long-term outcomes of mechanical valve replacement in patients with atrial fibrillation: impact of the maze procedure. Circulation. 2012;125:2071-80.

8. Ad N, Holmes SD, Massimiano PS, Rongione AJ, Fornaresio LM. Longterm outcome following concomitant mitral valve surgery and Cox maze procedure for atrial fibrillation. J Thorac Cardiovasc Surg. 2018;155: 983-94. 
9. Fukada J, Morishita K, Komatsu K, Sato H, Shiiku C, Muraki S, et al. Is atrial fibrillation resulting from rheumatic mitral valve disease a proper indication for the maze procedure? Ann Thorac Surg. 1998;65:1566-70.

10. Ishii Y, Nitta T. Atrial fibrillation surgery for patients with rheumatic valve disease. J Interv Card Electrophysiol. 2007;20:109-12.

11. Guilherme L, Cunha-Neto E, Coelho V, Snitcowsky R, Pomerantzeff PM, Assis RV, et al. Human heart-infiltrating T-cell clones from rheumatic heart disease patients recognize both streptococcal and cardiac proteins. Circulation. 1995;92:415-20.

12. Kim WK, Kim HJ, Kim JB, Jung SH, Choo SJ, Chung CH, et al. Clinical outcomes in 1731 patients undergoing mitral valve surgery for rheumatic valve disease. Heart. 2018;104:841-8.

13. Akins CW, Miller DC, Turina MI, Kouchoukos NT, Blackstone EH, Grunkemeier GL, et al. Guidelines for reporting mortality and morbidity after cardiac valve interventions. J Thorac Cardiovasc Surg. 2008;135:732-8.

14. Lee CH, Kim JB, Jung SH, Choo SJ, Chung CH, Lee JW. Left atrial appendage resection versus preservation during the surgical ablation of atrial fibrillation. Ann Thorac Surg. 2014;97:124-32.

15. Shen AY, Yao JF, Brar SS, Jorgensen MB, Chen W. Racial/ethnic differences in the risk of intracranial hemorrhage among patients with atrial fibrillation. J Am Coll Cardiol. 2007:50:309-15.

16. Gage BF, van Walraven C, Pearce L, Hart RG, Koudstaal PJ, Boode BS, et al. Selecting patients with atrial fibrillation for anticoagulation: stroke risk stratification in patients taking aspirin. Circulation. 2004;110:2287-92.

17. Calkins H, Brugada J, Packer DL, Cappato R, Chen SA, Crijns HJ, et al. HRS/ EHRA/ECAS expert consensus statement on catheter and surgical ablation of atrial fibrillation: recommendations for personnel, policy, procedures and follow-up. A report of the Heart Rhythm Society (HRS) task force on catheter and surgical ablation of atrial fibrillation developed in partnership with the European Heart Rhythm Association (EHRA) and the European Cardiac Arrhythmia Society (ECAS); in collaboration with the American College of Cardiology (ACC), American Heart Association (AHA), and the Society of Thoracic Surgeons (STS). Endorsed and approved by the governing bodies of the American College of Cardiology, the American Heart Association, the European Cardiac Arrhythmia Society, the European Heart Rhythm Association, the Society of Thoracic Surgeons, and the Heart Rhythm Society. Europace. 2007;9:335-79.

18. Kurth T, Walker AM, Glynn RJ, Chan KA, Gaziano JM, Berger K, et al. Results of multivariable logistic regression, propensity matching, propensity adjustment, and propensity-based weighting under conditions of nonuniform effect. Am J Epidemiol. 2006;163:262-70.

19. Remenyi B, ElGuindy A, Smith SC Jr, Yacoub M, Holmes DR Jr. Valvular aspects of rheumatic heart disease. Lancet. 2016;387:1335-46.

20. Global Burden of Disease Cancer Collaboration, Fitzmaurice C, Allen C, Barber RM, Barregard L, Bhutta ZA, et al. Global, regional, and national cancer incidence, mortality, years of life lost, years lived with disability, and disabilityadjusted life-years for 32 cancer groups, 1990 to 2015: a systematic analysis for the global burden of disease study. JAMA Oncol. 2017;3:524-48.
21. Zühlke L, Engel ME, Karthikeyan G, Rangarajan S, Mackie P, Cupido B, et al Characteristics, complications, and gaps in evidence-based interventions in rheumatic heart disease: the global rheumatic heart disease registry (the REMEDY study). Eur Heart J. 2015;36:1115-1122a.

22. Wang D, Liu M, Lin S, Hao Z, Tao W, Chen X, et al. Stroke and rheumatic heart disease: a systematic review of observational studies. Clin Neurol Neurosurg. 2013; $115: 1575-82$.

23. Bando K, Kobayashi J, Hirata M, Satoh T, Niwaya K, Tagusari O, et al. Early and late stroke after mitral valve replacement with a mechanical prosthesis: risk factor analysis of a 24-year experience. J Thorac Cardiovasc Surg. 2003;126: 358-64.

24. Benjamin EJ, Wolf PA, D’Agostino RB, Silbershatz H, Kannel WB, Levy D. Impact of atrial fibrillation on the risk of death: the Framingham Heart Study. Cir culation. 1998;98:946-52.

25. Murashita T, Rankin JS, Wei LM, Roberts HG, Alkhouli MA, Badhwar V. Oral anticoagulation may not be necessary for patients discharged in sinus rhythm after the Cox Maze IV procedure. J Thorac Cardiovasc Surg. 2018;155:997-1006.

26. Bando K, Kobayashi J, Kosakai Y, et al. Impact of Cox maze procedure on outcome in patients with atrial fibrillation and mitral valve disease. J Thorac Cardiovasc Surg. 2002; 124:575-83.

27. Sharma S, Sharma G, Hote M, et al. Light and electron microscopic features of surgically excised left atrial appendage in rheumatic heart disease patients with atrial fibrillation and sinus rhythm. Cardiovasc Pathol. 2014; 23:319-26.

28. Karthikeyan G, Ananthakrishnan R, Devasenapathy N, et al. Transient, subclinical atrial fibrillation and risk of systemic embolism in patients with rheumatic mitral stenosis in sinus rhythm. Am J Cardiol. 2014;114:869-74.

29. Labin JE, Haque N, Sinn LA, et al. The Cox-Maze IV procedure for atrial fibrillation is equally efficacious in patients with rheumatic and degenerative mitral valve disease. J Thorac Cardiovasc Surg. 2017;154:835-44.

30. Baek MJ, Na CY, Oh SS, et al. Surgical treatment of chronic atrial fibrillation combined with rheumatic mitral valve disease: effects of the cryo-maze procedure and predictors for late recurrence. Eur J Cardiothorac Surg. 2006; 30:728-36.

31. Wang H, Han J, Wang Z, et al. A prospective randomized trial of the cut-and-sew Maze procedure in patients undergoing surgery for rheumatic mitral valve disease. J Thorac Cardiovasc Surg. 2018;155:608-17.

32. Eguchi K, Ohtaki E, Matsumura T, et al. Pre-operative atrial fibrillation as the key determinant of outcome of mitral valve repair for degenerative mitral regurgitation. Eur Heart J. 2005;26:1866-72.

33. Wang TJ, Larson MG, Levy D, et al. Temporal relations of atrial fibrillation and congestive heart failure and their joint influence on mortality: the Framingham Heart Study. Circulation. 2003;107:2920-5.

Key Words: atrial arrhythmia ablation procedures, atrial fibrillation, mitral regurgitation, mitral stenosis, stroke 
Valve Related Outcomes
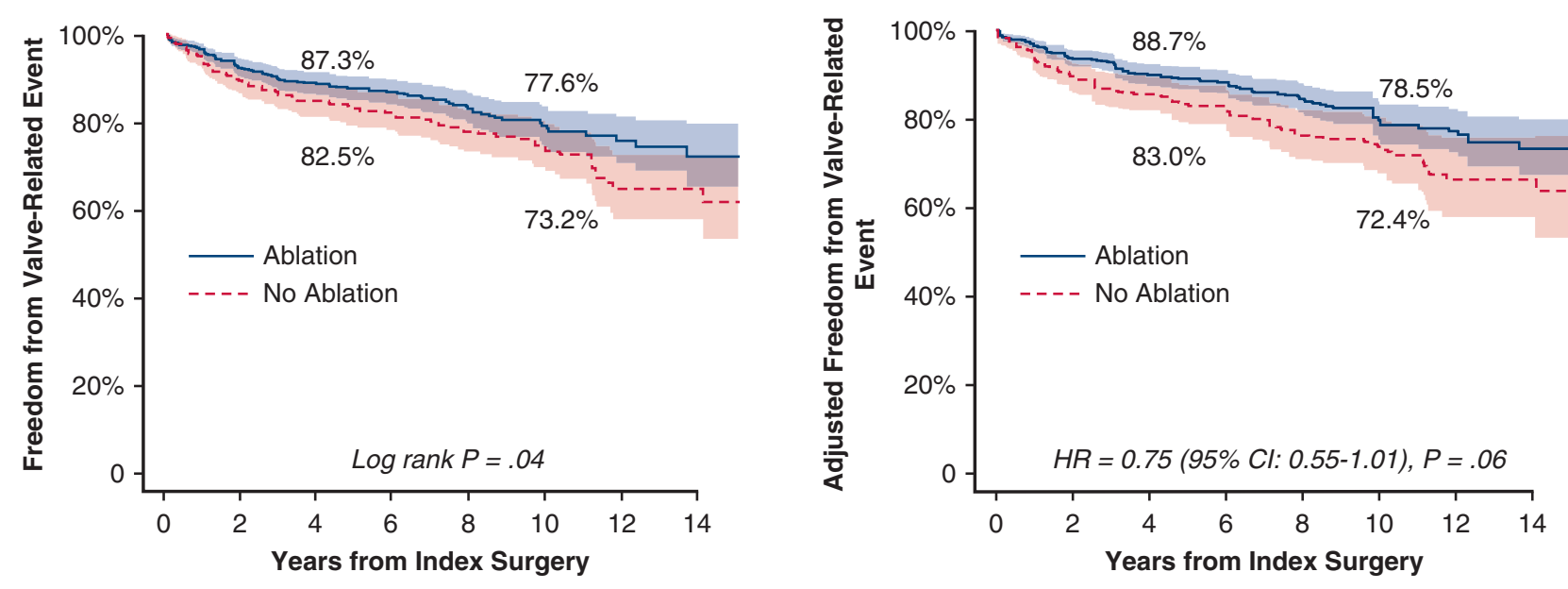

$\begin{array}{lllllllll}\text { Ablation } & 812 & 516 & 386 & 300 & 204 & 115 & 64 & 27\end{array}$

$\begin{array}{lllllllll}\text { Ablation } & 812 & 542 & 415 & 331 & 233 & 139 & 84 & 34\end{array}$

No Ablation $417 \quad 303 \quad 245 \quad 204 \quad 151 \quad 104 \quad 46 \quad 26$

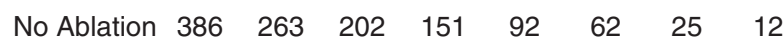

A

FIGURE E1. Kaplan-Meier plots for freedom from composite of valve-related complications. Blue, solid line = ablation group; red, dashed line = no ablation group. A, Kaplan-Meier plot for unadjusted outcomes. B, Kaplan-Meier plot for adjusted outcomes. $H R$, Hazard ratio; $C I$, confidence interval. 
TABLE E1. Baseline characteristics of the propensity score-matched patients

\begin{tabular}{|c|c|c|c|c|}
\hline & \multicolumn{4}{|c|}{ PS matching } \\
\hline & Ablation $(\mathrm{N}=\mathbf{2 6 5})$ & No ablation $(\mathrm{N}=\mathbf{2 6 5})$ & $P$ value & SMD \\
\hline \multicolumn{5}{|l|}{ Characteristics } \\
\hline Age, y & $54.7 \pm 10.9$ & $56.0 \pm 11.6$ & .19 & 0.113 \\
\hline Female gender, n (\%) & $175(66.0)$ & $180(67.9)$ & .71 & 0.040 \\
\hline Hemoglobin, g/dL & $13.1 \pm 1.8$ & $13.0 \pm 2.0$ & .66 & 0.039 \\
\hline Glomerular filtration rates, $\%$ & $79.9 \pm 22.5$ & $79.0 \pm 23.5$ & .65 & 0.039 \\
\hline Diabetes mellitus, n (\%) & $34(12.8)$ & $38(14.3)$ & .70 & 0.044 \\
\hline Hypertension, n (\%) & $61(23.0)$ & $64(24.2)$ & .84 & 0.027 \\
\hline ESRD, n $(\%)$ & $6(2.3)$ & $4(1.5)$ & .75 & 0.055 \\
\hline COPD, n $(\%)$ & $7(2.6)$ & $9(3.4)$ & .80 & 0.044 \\
\hline Dyslipidemia, n (\%) & $12(4.5)$ & $11(4.2)$ & $>.99$ & 0.018 \\
\hline PAOD, n $(\%)$ & $1(0.4)$ & 0 & $>.99$ & 0.087 \\
\hline Cerebrovascular disease, $\mathrm{n}(\%)$ & $6(2.3)$ & $5(1.9)$ & $>.99$ & 0.026 \\
\hline \multicolumn{5}{|l|}{ Echocardiographic data } \\
\hline MV diagnosis, n (\%) & & & .53 & 0.032 \\
\hline Predominant mitral regurgitation & $60(22.6)$ & $52(19.6)$ & & \\
\hline Predominant mitral stenosis & $111(41.9)$ & $123(46.4)$ & & \\
\hline Combined & $94(35.5)$ & $90(34.0)$ & & \\
\hline Mitral regurgitation grade, $\mathrm{n}(\%)$ & & & .08 & 0.064 \\
\hline None & $66(24.9)$ & $60(22.6)$ & & \\
\hline Mild & $45(17.0)$ & $67(25.3)$ & & \\
\hline Moderate & $63(23.8)$ & $59(22.3)$ & & \\
\hline Severe & $91(34.3)$ & $79(29.8)$ & & \\
\hline Severe TR, n (\%) & $121(45.7)$ & $119(44.9)$ & .93 & 0.015 \\
\hline LA dimension >60 mm, n (\%) & $132(49.8 \%)$ & $126(47.5 \%)$ & .66 & 0.045 \\
\hline LA thrombi, \% & $53(20.0 \%)$ & $56(21.1 \%)$ & .83 & 0.028 \\
\hline LV ejection fraction $<50 \%, \mathrm{n}(\%)$ & $78(29.4 \%)$ & $78(29.4 \%)$ & $>.99$ & 0 \\
\hline $\mathrm{MV}$ area $<1 \mathrm{~cm}^{2}, \mathrm{n}(\%)$ & $79(29.8 \%)$ & $74(27.9 \%)$ & .70 & 0.042 \\
\hline Systolic PAP >50 mm Hg, n (\%) & $52(19.6 \%)$ & $46(17.4 \%)$ & .58 & 0.058 \\
\hline
\end{tabular}

$P S$, Propensity score; $S M D$, standardized mean difference; $E S R D$, end-stage renal disease; $C O P D$, chronic obstructive pulmonary disease; $P A O D$, peripheral arterial obstructive disease; $M V$, mitral valve; $T R$, tricuspid regurgitation; $L A$, left atrial; $L V$, left ventricular; $P A P$, pulmonary artery pressure.

TABLE E2. Surgical periods and procedures of the propensity score-matched patients

\begin{tabular}{|c|c|c|c|c|}
\hline & \multicolumn{4}{|c|}{ PS matching } \\
\hline & Ablation $(N=265)$ & No ablation $(\mathrm{N}=\mathbf{2 6 5})$ & $P$ value & SMD \\
\hline \multicolumn{5}{|l|}{ Operations } \\
\hline Years at operation & & & .99 & 0.030 \\
\hline Quintile range $1(1997-2001, \mathrm{n}=245)$ & $52(19.6)$ & $47(17.7)$ & & \\
\hline Quintile range $2(2002-2005, \mathrm{n}=245)$ & $70(26.4)$ & $72(27.2)$ & & \\
\hline Quintile range $3(2005-2008, \mathrm{n}=245)$ & $66(24.9)$ & $68(25.7)$ & & \\
\hline Quintile range $4(2008-2012, \mathrm{n}=245)$ & $45(17.0)$ & $45(17.0)$ & & \\
\hline Quintile range $5(2012-2016, \mathrm{n}=249)$ & $32(12.1)$ & $33(12.5)$ & & \\
\hline MV procedures & & & .78 & 0.051 \\
\hline Valve repair procedure & $21(7.9)$ & $17(6.4)$ & & \\
\hline Mechanical valve replacement & $189(71.3)$ & $190(71.7)$ & & \\
\hline Bioprosthetic valve replacement & $55(20.8)$ & $58(21.9)$ & & \\
\hline \multicolumn{5}{|l|}{ Combined procedures } \\
\hline Atrial septal defect closure & $10(3.8)$ & $7(2.6)$ & .62 & 0.064 \\
\hline Tricuspid valve plasty, n (\%) & $129(48.7)$ & $128(48.3)$ & $>.99$ & 0.008 \\
\hline Aortic valve replacement, $\mathrm{n}(\%)$ & $88(33.2)$ & $79(29.8)$ & .45 & 0.073 \\
\hline CABG, $n(\%)$ & $15(5.7)$ & $14(5.3)$ & $>.99$ & 0.017 \\
\hline Aortic procedures, n (\%) & $7(2.6)$ & $5(1.9)$ & .77 & 0.051 \\
\hline
\end{tabular}

$P S$, Propensity score; $S M D$, standardized mean difference; $M V$, mitral valve; $C A B G$, coronary artery bypass grafting. 
TABLE E3. Reliability tests of propensity score matching and inverse probability of treatment weighting methods in overall and subgroup analyses

\begin{tabular}{|c|c|c|c|c|}
\hline & Overall & Repair & Mechanical & Bioprosthetic \\
\hline Hosmer-Lemeshow goodness of fit $P$ value & 0.61 & 0.89 & 0.21 & 0.27 \\
\hline \multirow[t]{3}{*}{ Area under the curve (C-statistics) } & 0.837 & 0.899 & 0.824 & 0.852 \\
\hline & \multicolumn{4}{|c|}{ SMD in weighted subgroup analyses } \\
\hline & Repair & & Mechanical & Bioprosthetic \\
\hline \multicolumn{5}{|l|}{ Characteristics } \\
\hline Age & 0.190 & & 0.001 & 0.287 \\
\hline Female gender & 0.358 & & 0.035 & 0.045 \\
\hline Hemoglobin & 0.314 & & 0.117 & 0.228 \\
\hline Glomerular filtration rates & 0.240 & & 0.090 & 0.039 \\
\hline Diabetes mellitus & 0.607 & & 0.076 & 0.052 \\
\hline Hypertension & 0.444 & & 0.022 & 0 \\
\hline COPD & 0.324 & & 0.034 & 0.077 \\
\hline Dyslipidemia & 0.239 & & 0.038 & 0.411 \\
\hline PAOD & 0 & & 0.059 & 0 \\
\hline Cerebrovascular disease & 0.097 & & 0.058 & 0.014 \\
\hline \multicolumn{5}{|l|}{ Echocardiographic data } \\
\hline MV diagnosis* & 0.353 & & 0.097 & 0 \\
\hline Severe TR & 0.793 & & 0.025 & 0.154 \\
\hline LA dimension & 0.402 & & 0.075 & 0.047 \\
\hline LA thrombi & 0.383 & & 0.069 & 0.061 \\
\hline LV ejection fraction & 0.393 & & 0.023 & 0.079 \\
\hline MV area & 0.323 & & 0.011 & 0.071 \\
\hline Systolic PAP & 0.407 & & 0.050 & 0.011 \\
\hline
\end{tabular}

$S M D$, Standardized mean difference; $C O P D$, chronic obstructive pulmonary disease; $P A O D$, peripheral arterial obstructive disease; $M V$, mitral valve; $T R$, tricuspid regurgitation; $L A$, left atrial; $L V$, left ventricle; $P A P$, pulmonary artery pressure. ${ }^{*} \mathrm{MV}$ diagnosis: predominant $\mathrm{MV}$ regurgitation or stenosis.

TABLE E4. Details of early clinical outcomes in overall cohort

\begin{tabular}{lcrr}
\hline & Ablation $(\mathbf{n = 8 1 2})$ & No ablation $(\mathbf{n}=\mathbf{4 1 7})$ & $\boldsymbol{P}$ value \\
\hline Adverse outcomes, $\mathrm{n}(\%)$ & & & \\
$\quad$ Early mortality & $10(1.2)$ & $10(2.4)$ & .13 \\
Early major morbidities & & & \\
$\quad$ Low cardiac output syndrome & $6(0.7)$ & $2(0.5)$ & .92 \\
Stroke & $4(0.5)$ & $2(0.5)$ & $>.99$ \\
Surgical site bleeding & $2(0.2)$ & $1(0.2)$ & $>.99$ \\
\hline
\end{tabular}

TABLE E5. Risk analyses for thromboembolic events depending on the postoperative atrial fibrillation recurrence

\begin{tabular}{|c|c|c|c|c|}
\hline & \multicolumn{4}{|c|}{ AF status } \\
\hline & Ablation & No ablation & OR $(95 \% \text { CI })^{*}$ & $P$ value \\
\hline \multicolumn{5}{|l|}{ AF/total (\%) } \\
\hline Immediate postoperative status & $19 / 812(2.3)$ & $317 / 417$ (76.0) & $0.008(0.005-0.013)$ & $<.001$ \\
\hline Postoperative 3 y & $103 / 593(17.4)$ & $215 / 337(63.8)$ & $0.12(0.09-0.15)$ & $<.001$ \\
\hline Postoperative $6 \mathrm{y}$ & $89 / 385(23.1)$ & $183 / 254(72.0)$ & $0.10(0.07-0.15)$ & $<.001$ \\
\hline Postoperative $9 \mathrm{y}$ & $93 / 237(39.2)$ & $164 / 179(91.6)$ & $0.04(0.015-0.09)$ & $<.001$ \\
\hline
\end{tabular}

$P$ for interaction (between time and group variables) $<.001 . A F$, Atrial fibrillation; $O R$, odds ratio; $C I$, confidence interval. *ORs of the no ablation group are 1.00 . 
TABLE E6. Risk analyses for adverse clinical outcomes in propensity score-matched cohort: Ablation versus no ablation

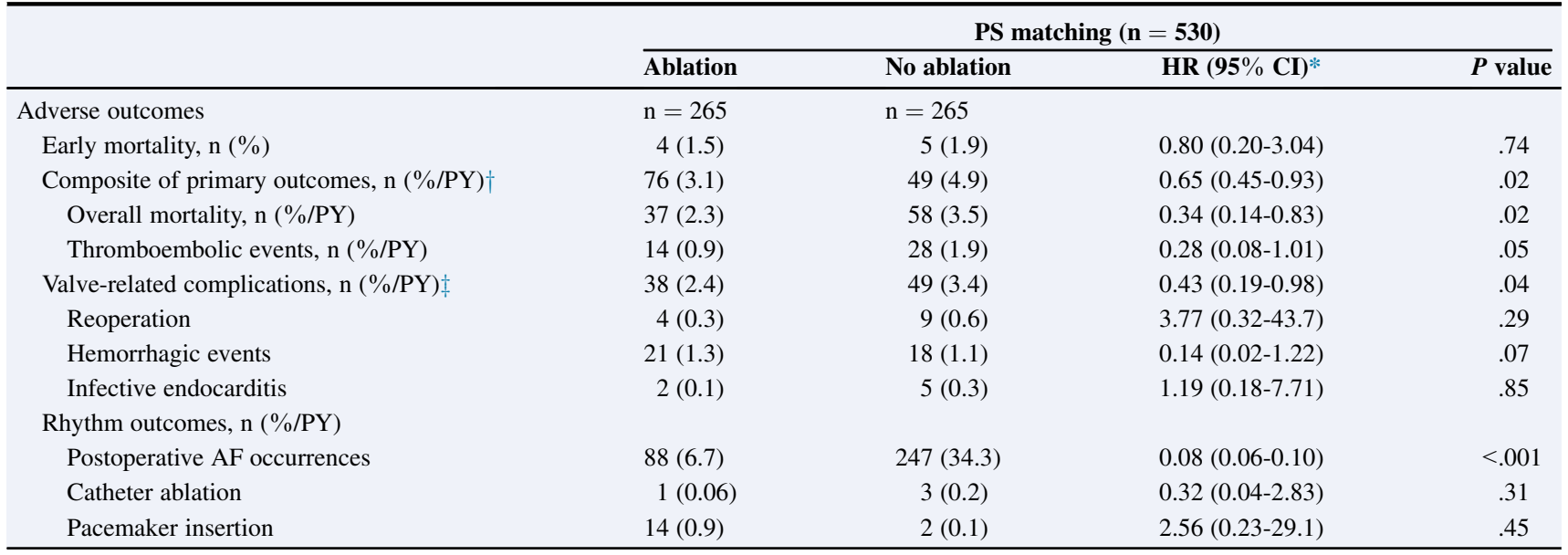

PS, Propensity score; $H R$, hazard ratio; $C I$, confidence interval; $P Y$, patient-year; $A F$, atrial fibrillation. *ORs for early mortality and HRs for other outcomes (HRs of the no ablation group are 1.00). $\dagger$ The composite of primary outcomes includes mortality and thromboembolic outcomes. $\ddagger$ The composite outcome of valve-related complications includes reoperation of the MV, thromboembolic events, anticoagulation-related bleeding complications, and infective endocarditis

TABLE E7. Risk of mortality of the time-varying complications of thromboembolic events and stroke

\begin{tabular}{|c|c|c|c|c|}
\hline & \multicolumn{4}{|c|}{ All cohort $(n=1229)$} \\
\hline & Ablation $(\mathrm{n}=\mathbf{8 1 2})$ & No ablation $(n=417)$ & HR $(95 \% \text { CI })^{*}$ & $P$ value \\
\hline Thromboembolic events, n ( $\% / P Y)$ & $35(0.85)$ & $31(1.13)$ & & \\
\hline Thromboembolic events to death & $7(0.17)$ & $14(0.49)$ & $3.08(1.92-4.93)$ & $<.001$ \\
\hline Stroke, $\mathrm{n}(\% / \mathrm{PY})$ & $20(0.49)$ & $24(0.87)$ & & \\
\hline Stroke to death & $5(0.12)$ & $11(0.38)$ & $3.97(2.36-6.69)$ & $<.001$ \\
\hline Peripheral neuropathy, n (\%/PY) & $5(0.12)$ & $2(0.07)$ & & \\
\hline Resolve within 1 mo, n (\%/PY) & $10(0.24)$ & $5(0.18)$ & & \\
\hline
\end{tabular}

$H R$, Hazard ratio; $C I$, confidence interval; $P Y$, patient-year. *Reference is no occurrence of thromboembolic events.

TABLE E8. Risk analyses for adverse clinical outcomes in weighted subgroups (inverse probability of treatment weighting): Ablation versus no ablation

\begin{tabular}{|c|c|c|c|c|c|c|}
\hline & \multicolumn{2}{|c|}{ Repair } & \multicolumn{2}{|c|}{ Mechanical } & \multicolumn{2}{|c|}{ Bioprosthetic } \\
\hline & HR $(95 \%$ C)I* & $P$ value & HR $(95 \% \text { CI })^{*}$ & $P$ value & HR $(95 \% \text { CI })^{*}$ & $P$ value \\
\hline \multicolumn{7}{|l|}{ Adverse outcomes } \\
\hline Early mortality & $1.12(0.72-1.74)$ & .62 & $1.05(0.78-1.40)$ & .75 & $0.92(0.59-1.41)$ & .69 \\
\hline Composite primary outcomes $\dagger$ & $0.17(0.06-0.52)$ & .002 & $0.53(0.39-0.73)$ & $<.001$ & $0.67(0.41-1.08)$ & .09 \\
\hline Overall mortality & $0.18(0.06-0.55)$ & .003 & $0.61(0.41-0.91)$ & .01 & $0.71(0.43-1.17)$ & .18 \\
\hline Thromboembolic events & $0.20(0.02-2.25)$ & .19 & $0.43(0.26-0.69)$ & $<.001$ & $0.54(0.18-1.65)$ & .28 \\
\hline Valve-related complications ${ }_{\ddagger}^{\dagger}$ & $0.27(0.08-0.84)$ & .02 & $0.71(0.50-0.99)$ & .05 & $0.60(0.28-1.29)$ & .19 \\
\hline Reoperation & NA & NA & $0.37(0.10-1.45)$ & .16 & $0.58(0.10-3.38)$ & .54 \\
\hline Hemorrhagic events & $0.07(0.01-0.43)$ & .004 & $1.31(0.77-2.22)$ & .32 & $0.89(0.23-3.50)$ & .87 \\
\hline Infective endocarditis & NA & NA & $0.71(0.17-2.92)$ & .63 & $0.61(0.07-5.49)$ & .66 \\
\hline \multicolumn{7}{|l|}{ Rhythm outcomes } \\
\hline Postoperative AF & $0.12(0.07-0.22)$ & $<.001$ & $0.21(0.18-2.64)$ & $<.001$ & $0.16(0.11-0.23)$ & $<.001$ \\
\hline Catheter ablation & NA & NA & $0.13(0.01-1.49)$ & .10 & NA & NA \\
\hline Pacemaker insertion & $0.46(0.05-3.95)$ & .48 & $5.77(1.75-19.0)$ & .004 & $10.3(0.49-99)$ & .13 \\
\hline
\end{tabular}

HR, Hazard ratio; $C I$, confidence interval; $N A$, not available; $A F$, atrial fibrillation. *ORs for early mortality and HRs for other outcomes (HRs of the no ablation group are 1.00 ). $\dagger$ The composite of primary outcomes includes mortality and thromboembolic outcomes. $\ddagger$ The composite outcome of valve-related complications includes reoperation of the MV, thromboembolic events, anticoagulation-related bleeding complications, and infective endocarditis. 
TABLE E9. Sensitivity analyses

\begin{tabular}{|c|c|c|c|c|}
\hline & \multicolumn{2}{|c|}{ Mortality } & \multicolumn{2}{|c|}{ Thromboembolic events } \\
\hline & $\overline{\text { HR }(95 \% \mathbf{C I})^{*}}$ & $P$ value & HR $\left(95 \%\right.$ CI) ${ }^{*}$ & $P$ value \\
\hline LA appendage resection & $1.12(0.69-1.82)$ & .65 & $1.07(0.51-2.23)$ & .85 \\
\hline Isolated LA ablation & $0.73(0.73-1.81)$ & .50 & $0.87(0.27-2.80)$ & .81 \\
\hline Cut-and-sew technique & $0.85(0.52-1.39)$ & .53 & $0.53(0.22-1.27)$ & .16 \\
\hline Nitrogen cryoablation & $0.83(0.53-1.30)$ & .42 & $0.57(0.28-1.19)$ & .14 \\
\hline Microwave ablation & $0.71(0.26-1.95)$ & .51 & $1.24(0.40-3.86)$ & .71 \\
\hline
\end{tabular}

$H R$, Hazard ratio; $C I$, confidence interval; $L A$, left atrium. *Reference is no performance of the procedures. 